\title{
Experimental Investigation of Char Generated from Co-Pyrolysis of Coal and Appalachian Hardwoods
}

\author{
$\underline{\text { Steven L. Rowan }}^{1,2}$ \\ steve.rowan@mail.wvu.edu \\ (304) 2933197 \\ Fan $\mathrm{Wu}^{3}$ \\ fawu@mix.wvu.edu \\ Ismail B. Celik ${ }^{4}$ \\ ismail.celik@mail.wvu.edu \\ Nathan T. Weiland ${ }^{5}$ \\ nathan.weiland@mail.wvu.edu \\ ${ }^{1,3,4,5}$ Department of Mechanical and Aerospace Engineering, West Virginia University, $3^{\text {rd }}$ floor \\ Engineering Science Building, Morgantown, WV 26506, USA \\ ${ }^{2}$ Corresponding author.
}

\begin{abstract}
In recent years, there has been increased interest in the co-combustion and co-gasification of coal and biomass materials in many industrial applications. The primary driving force behind this interest lays in the fact that co-combustion and co-gasification of coal biomass material is viewed to be a more carbonneutral approach to processes typically used for power generation, as well as generation of syngas and other coal-derived chemicals. With the addition of renewable biomass materials to the coal used in these processes, the net amount of carbon dioxide released to the atmosphere is effectively reduced due to the assumption that replenishment of the biomass via replanting will lead to carbon dioxide removal via photosynthesis.

The current study investigates co-pyrolysis of coal and biomass feedstocks, a precursor to the cocombustion or co-gasification reactions when both materials are fed together into the combustor or gasifier. Experiments have been conducted in which different mixtures of typical West Virginia power plant blend coals and Appalachian hardwoods have undergone pyrolysis using a tube furnace.

Measurements were made with samples that contained $100 \%$ coal, $100 \%$ biomass as well as a $50 \%$ coal / $50 \%$ biomass mixture. In addition, two different particle size ranges were used in order to examine the effect of particle size on the resulting pyrolysis products. In each experiment, the coal and biomass mixtures were heated to $500{ }^{\circ} \mathrm{C}$ in a nitrogen atmosphere. Samples of the resulting solid char were collected and analyzed via ultimate and proximate analysis, and Fourier Transform Infra-Red spectrometry (FT-IR).

Numerous authors have debated whether or not the addition of biomass material to coal generates a synergistic, non-linear effect upon the resulting pyrolysis products. The data obtained during the current study suggests that varying the biomass content in the initial feed stock show linearity with respect to the proximate and ultimate (elemental) analysis results of the produced chars; however, non-linearities can be
\end{abstract}


seen in the tar and char yields, and in the functional group structure of the chars, as revealed by FT-IR analysis of the solid char samples.

Keywords: coal, biomass, pyrolysis

\section{Introduction}

Due to increasing economic growth around the world, the demand for energy is increasing. As a result, there has been an increasing interest in utilizing abundant biomass supplies for energy production. Traditional fossil fuels, such as coal, release large amounts of carbon dioxide and other environmentally unfriendly gases into the atmosphere. Co-firing of biomass with coal has been steadily gaining in popularity due to the shorter life cycle of biomass as compared to fossil fuels such as coal [1]. Since the biomass materials can be regrown at a much faster rate than traditional fossil fuels are formed, biomass is considered to be a renewable resource, and it is one that is considered to have a smaller greenhouse gas footprint due to the fact that the biomass material will remove carbon dioxide from the atmosphere via photosynthesis. Because of this shorter life cycle, if biomass is used in conjunction with coal to generate power, it will not only reduce the consumption of coal, but also reduce the environmental pollution and greenhouse effects of fossil fuel combustion [2], thus providing a more carbon-neutral source of energy.

In addition to being considered one of the initial phases of combustion of fossil fuels and biomass, pyrolysis is also used industrially as a pre-treatment prior to combustion in order to improve the energy density of fuels, and for the generation of coke, syngas and other coal-derived chemicals. In recent years, extensive efforts have been made to study the effects of the addition of biomass material to coal on the resulting yields of char, tar and volatile gases during coal pyrolysis. Many researchers, such as Aboyade, et al. [3], Haykiri-Acma, et al. [4] and Ulloa, et al. [5] have reported that thermo-gravimetric analysis (TGA) of coal and biomass co-pyrolysis under non-isothermal conditions shows an increase in the release of volatiles and a decrease in char yields when coal is pyrolyzed with biomass. Aboyade, et. al. [3] suggests that this is due to synergetic reactions that take place between the coal and biomass at temperatures between 300 and $500^{\circ} \mathrm{C}$. However, Weiland, et al. [6] and other authors $[1,7,8]$ have shown that under certain conditions, the product yields from pyrolysis of coal and biomass can be determined from the weighted averages of the individual components of the mixture. Weiland, et al. [6] studied the thermochemical conversion of bituminous coal and switchgrass mixtures in a drop-tube furnace operating at $900^{\circ} \mathrm{C}$. Their study considered gas composition, as well as ultimate analysis of char and tar products, and ash composition of the char, and concluded that the distribution of products appeared to be linear with respect to the weight percentage of biomass in the feedstock. Later studies [9] showed that significant nonlinearities can exist under high heating rate conditions with lower rank coals, where it is suggested that hydrogen from rapid biomass pyrolysis stabilizes coal pyrolysis radicals to form tar rather than secondary char in the absence of biomass. The TGA studies of Haykiri-Acma, et al. [4] support the effect of coal rank and heating rate on co-pyrolysis nonlinearities, as volatilization of lower rank coals occurs at lower temperatures that may overlap with biomass volatilization, leading to nonlinearity as the coal and biomass volatiles interact.

Most of these previous studies have focused on either the composition of the volatile gases released, or else on the weight loss characteristics during the pyrolysis process. With the exception of [6], the publications cited in this paper devote little attention to studying the effects of co-pyrolysis upon the resulting char materials. It is only logical that if there are indeed synergistic non-linear effects upon the evolved gases and weight loss characteristics during pyrolysis, there should be a corresponding nonlinearity present in the char materials. Similarly if, as some authors claim, the effects of co-pyrolysis can be quantified as a linear combination of the respective coal/biomass mass fractions, this should also be reflected within the solid char. The current study aims at finding some explanation, and answers, to the above mentioned issues. 


\section{Materials and Methods}

The experimental system is shown in Figure 1. A Lucifer tube furnace with three ceramic heating elements mounted in a vertical position is used to heat the pyrolysis samples which are placed inside a $3 / 4$ inch ID stainless steel tube section which serves as the pyrolysis chamber. This chamber is suspended within the tube furnace such that the sample is located in the center of the central heating element. The top of the pyrolysis chamber is connected via steel tubing to a nitrogen gas supply. The bottom of the chamber is likewise connected to a condenser via steel tubing. During operation of the furnace, nitrogen gas flows through the pyrolysis chamber, thus forcing out any volatile gases and vaporized tar materials. These gases pass through the condenser, where liquid tars are condensed and collected for later measurement. After leaving the condenser, the exhaust gases pass through a series of valves that allow the gas to be collected for further analysis, or be passed through a scrubber and vented through a fume hood. Internal and external reactor chamber, and exhaust gas temperatures are recorded during the experimental runs via K-type thermocouples connected to a portable data acquisition system from Omega Engineering.

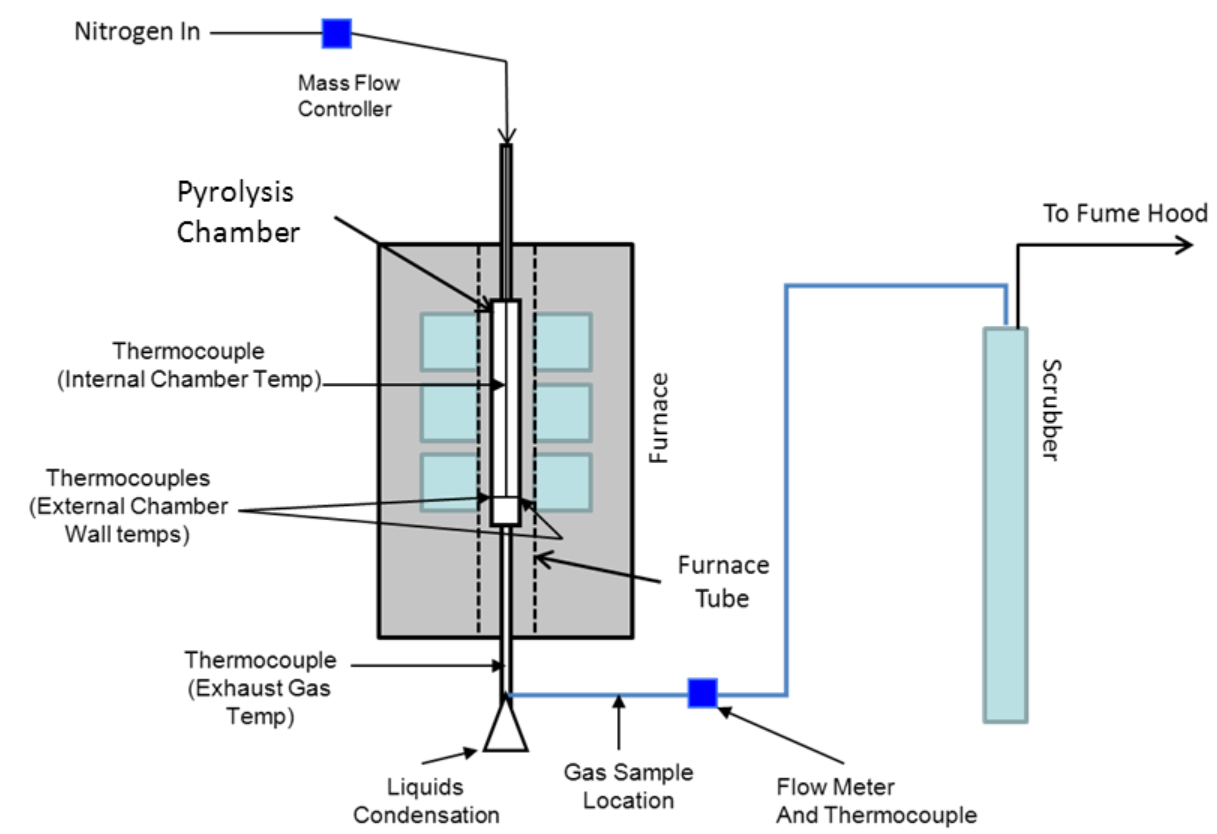

Figure 1.Pyrolysis Furnace System Diagram

For the experimental data presented, samples of eastern bituminous coal (Pittsburgh \#8) obtained from Consol Energy's Blacksville, WV mine, as well as sawdust obtained from local sources containing Appalachian hardwoods, were ground and sieved to size ranges of 850-1000 and 300-500 microns. Each material was characterized via proximate and ultimate analysis, and the results are shown in Table 1 (including the experimental uncertainty due to error propagation). The coal has significantly lower amounts of moisture and volatile compounds when compared to the biomass, but has significantly greater amounts of ash and fixed carbon. Each of the experimental runs were conducted with 5 grams of either the coal or biomass, or with 2.5 grams of each material combined. These samples were then placed inside the reaction chamber and heated to a temperature of $500{ }^{\circ} \mathrm{C}$ with nitrogen purge gas flow rates of 200 $\mathrm{cm}^{3} / \mathrm{min}$. The temperature control system on the Lucifer furnace does not allow for precise control of the heating rate, but manual observation suggests heating rates in the range of $15-20^{\circ} \mathrm{C} / \mathrm{min}$. 
Upon completion of each run, the furnace and reactor chamber were allowed to cool back to ambient temperature and the remaining char and condensed tar products were collected, weighed, and analyzed.

Table 1: Proximate and ultimate analyses of coal and biomass feedstocks (wt. \%, dry basis)

$\begin{array}{lllllllll} & \text { Volatiles } & \text { Ash } & \text { Fixed Carbon } & \text { N } & \text { C } & \text { H } & \text { S } & \text { O (by diff.) } \\ \text { Coal } & 36.01 \pm 0.89 & 10.65 \pm 0.94 & 53.34 \pm 0.94 & 2.92 \pm 0.15 & 72.85 \pm 1.23 & 5.47 \pm 0.07 & 2.44 \pm 0.12 & 16.12 \pm 1.25 \\ \text { Biomass } & 82.37 \pm 0.05 & 0.37 \pm 0.23 & 17.27 \pm 0.23 & 2.30 \pm 0.05 & 47.23 \pm 0.04 & 6.26 \pm 0.06 & 0.00 \pm 0.00 & 44.21 \pm 0.09\end{array}$

\section{Results and Discussion}

During pyrolysis, the material is heated in order to drive off the moisture that is present within the material, as well as any volatile compounds that are chemically bound within the structure of the material being heated. As a result of this heating, these volatiles are released in either liquid (tar) or gas phase, or condense within the parent material to form secondary char.

\subsection{Char and Tar Yields}

During the course of the experiments, the masses of the collected char and liquid tar products collected were measured and recorded. This char and tar yield data are presented (along with experimental uncertainty due to error propagation) in Table 2. Additionally, a weighted average (based on a linear combination of the char and tar yields for the pure coal- and pure biomass-derived products) is provided for comparison to the 50/50 mixture experimental results. When the coal/biomass mixture results are compared to this linear combination of the pure materials, it can be seen that the experimental char yields are higher than those predicted by the weighted average. The difference is approximately 15 percent of the predicted value. Similarly, the experimental tar yields for the 50/50 mixture of coal and biomass exceed the predicted value by as much as 60 percent in the case of the smaller particle sizes, and approximately 28 percent for the larger particles. These differences are too large to attribute solely to experimental error, suggesting a possible non-linear relationship for char and tar production. Comparing the results between particle sizes, more tar and slightly less char are produced for the smaller particle sizes, consistent with reduced secondary char formation resulting from lower volatile residence time in the char.

Table 2. Char and tar mass yields upon heating to $500^{\circ} \mathrm{C}$

\begin{tabular}{llll}
\hline Particle size & Mixture & Char \% & Tar \% \\
Range $(\mu \mathrm{m})$ & & Yield & Yield \\
& 100\% Coal & $59.2 \pm 0.33$ & $4.6 \pm 0.20$ \\
$850-1000$ & 100\% Biomass & $22.4 \pm 0.29$ & $5.4 \pm 0.20$ \\
& 50/50 Coal/Biomass & $46.8 \pm 0.31$ & $6.4 \pm 0.20$ \\
& Weighted Average & $40.8 \pm 0.44$ & $5.0 \pm 0.28$ \\
\hline \multirow{3}{*}{$300-500$} & 100\% Coal & $56.4 \pm 0.32$ & $17.6 \pm 0.21$ \\
& 100\% Biomass & $22.0 \pm 0.29$ & $11.2 \pm 0.20$ \\
& 50/50 Coal/Biomass & $45.0 \pm 0.31$ & $22.8 \pm 0.21$ \\
& Weighted Average & $39.2 \pm 0.43$ & $14.49 \pm 0.29$ \\
\hline
\end{tabular}

In spite of the similar heating rates, the increases in co-pyrolysis char yield seen in Table 2 differ from the TGA-type experiments in which co-pyrolysis typically reduces char yields [3-5]. This can be attributed to 
the much smaller particle sizes $(50-250 \mu \mathrm{m})$ and samples sizes $(5-40 \mathrm{mg})$ used in the TGA, as compared to these experiments. Larger particle and sample sizes lead to significantly higher contact time between volatiles and char in this study, and likely results in significant secondary char formation.

\subsection{Proximate Analysis}

Table 3 presents the proximate analysis of the resulting chars after pyrolysis (including the experimental uncertainty due to measurement error propagation), as well as a weighted average for comparison to the 50/50 mixture. As expected, there exist significant differences in the distribution of volatiles, ash and fixed carbon between the coal and biomass chars. As the material is heated during the pyrolysis process, there is a resulting decrease in the amount of volatiles, with corresponding increases in the percentage of ash and fixed carbon. The coal undergoes a reduction in volatiles of $64 \%$ (36.01\% to $12.77 \%$ ) and $60 \%$ (36.01\% to $14.36 \%$ ) of the original feed sample for the larger and smaller particle size ranges, respectively. In comparison, the biomass material experiences volatile content reductions of $74 \%$ $(82.37 \%$ to $21.06 \%)$ and $72 \%$ ( $82.37 \%$ to $22.42 \%)$ for the larger and smaller particle size ranges, respectively. In general, it can be concluded that the biomass material experiences much greater levels of devolatilization during heating than the coal, as expected and shown by the relatively smaller char yields in Table 2.

In addition to the pure coal and pure biomass samples, a 50/50 coal-to-biomass mixture was also tested. The proximate analysis results for these mixtures are also presented, along with a char yield massweighted average of the pure coal char and pure biomass char results. Comparing the proximate analysis results for the coal and biomass mixture to the weighted average (of char mass) of the pure char mixtures, there are slight differences in the distribution of volatiles, ash and fixed carbon; but these fall within the margins of experimental error, as shown by the numbers following the \pm sign in table 3 . It can be concluded from this that there is the possible existence of a linear relationship between the coal and biomass with respect to the distribution of volatiles, ash and fixed carbon present in the resulting char.

Table 3.Proximate analysis results for pyrolysis chars (wt. \%, dry basis)

\begin{tabular}{lllll}
\hline Particle size & Mixture & Volatiles & Ash & Fixed \\
Range $(\mu \mathrm{m})$ & & & & Carbon \\
& 100\% Coal & $12.77 \pm 0.97$ & $14.73 \pm 0.99$ & $72.50 \pm 0.99$ \\
$850-1000$ & 100\% Biomass & $21.06 \pm 0.13$ & $2.55 \pm 0.36$ & $76.38 \pm 0.36$ \\
& 50/50 Coal/Biomass & $14.46 \pm 0.50$ & $12.75 \pm 0.71$ & $72.79 \pm 0.71$ \\
& Weighted Average & $15.01 \pm 0.75$ & $11.45 \pm 0.74$ & $73.54 \pm 1.08$ \\
\hline \multirow{3}{*}{$300-500$} & 100\% Coal & $14.36 \pm 1.83$ & $16.39 \pm 1.35$ & $69.25 \pm 1.35$ \\
& 100\% Biomass & $22.42 \pm 0.15$ & $2.69 \pm 0.40$ & $74.89 \pm 0.40$ \\
& 50/50 Coal/Biomass & $15.40 \pm 0.74$ & $11.80 \pm 0.86$ & $72.81 \pm 0.86$ \\
& Weighted Average & $16.59 \pm 1.33$ & $12.60 \pm 0.99$ & $70.81 \pm 1.25$ \\
\hline
\end{tabular}

\subsection{Ultimate Analysis}

Another common analysis technique used when characterizing coal is ultimate, or elemental, analysis. In general, this analysis method yields information of the percentage of nitrogen, carbon, hydrogen and sulfur within the sample, although oxygen can also be determined to reasonable accuracy by difference. The resulting pyrolysis chars for each experimental run were subjected to ultimate analysis and the results are provided in Table 4 . After being heated to a temperature of $500{ }^{\circ} \mathrm{C}$, the data suggests that the elemental composition of the coal does not change significantly. The coal shows evidence of minor losses in hydrogen and oxygen ( $\sim 1 \%$ for oxygen and $\sim 2 \%$ for hydrogen), which tend to evolve at temperatures 
above $500{ }^{\circ} \mathrm{C}$, while exhibiting an overall increase in the percentage of carbon $(0-1 \%)$ and sulfur $(0.2-$ $0.8 \%)$. Finally, the data shows that, in the case of samples containing just coal, there was a decrease in nitrogen content for the larger particle size range ( $\sim .4 \%)$, while simultaneously showing an increase in nitrogen in the smaller particle sizes ( 0.23). In comparison, after being heated to $500{ }^{\circ} \mathrm{C}$, the biomassonly samples exhibit increases in the percentage of carbon $(\sim 35-36 \%)$, as well as significant decreases in hydrogen $(\sim 3 \%)$ and oxygen $(\sim 35-36 \%)$, and moderate decreases in nitrogen content $(\sim 0.4-0.5 \%)$.

Comparison of the measured elemental composition of the char resulting from the heating of the coal and biomass mixture with a weighted average of the coal- and biomass-only samples suggests that the mixture behaves in a nearly linear fashion, as seen during consideration of the proximate analysis data. This is consistent with the TGA studies of Haykiri-Acma, et al. [4] for low heating rate co-pyrolysis of biomass with higher-rank coal, similar to the conditions studied here.

Table 4.Ultimate analysis of pyrolysis chars (wt. \%, dry basis)

\begin{tabular}{lllllll}
\hline $\begin{array}{l}\text { Particle size } \\
\text { Range }(\mu \mathrm{m})\end{array}$ & Mixture & Nitrogen & Carbon & Hydrogen & Sulfur & $\begin{array}{l}\text { Oxygen } \\
\text { (by diff.) }\end{array}$ \\
& & & & & & \\
\multirow{3}{*}{$850-1000$} & 100\% Coal & $2.5 \pm 0.43$ & $76.41 \pm 0.83$ & $3.3 \pm 0.05$ & $2.63 \pm 0.19$ & $15.16 \pm 0.96$ \\
& 100\% Biomass & $2.4 \pm 0.05$ & $83.21 \pm 0.12$ & $3.11 \pm 0.01$ & $0 \pm 0.00$ & $11.28 \pm 0.13$ \\
& 50/50 Coal/Biomass & $2.88 \pm 0.01$ & $78.07 \pm 1.69$ & $3.09 \pm 0.06$ & $1.35 \pm 0.12$ & $14.61 \pm 1.70$ \\
& Weighted Average & $2.47 \pm 0.32$ & $77.82 \pm 1.04$ & $3.25 \pm 0.09$ & $1.91 \pm 0.14$ & $14.55 \pm 1.10$ \\
\hline \multirow{3}{*}{$300-500$} & 100\% Coal & $3.15 \pm 0.04$ & $72.33 \pm 0.24$ & $3.3 \pm 0.02$ & $3.31 \pm 0.21$ & $17.91 \pm 0.32$ \\
& 100\% Biomass & $2.53 \pm 0.05$ & $82.1 \pm 0.12$ & $3.08 \pm 0.01$ & $0 \pm 0.00$ & $12.29 \pm 0.13$ \\
& 50/50 Coal/Biomass & $2.65 \pm 0.01$ & $76.41 \pm 0.59$ & $3.35 \pm 0.07$ & $1.97 \pm 0.15$ & $15.62 \pm 0.61$ \\
& Weighted Average & $2.98 \pm 0.75$ & $75.07 \pm 0.81$ & $3.24 \pm 0.09$ & $2.38 \pm 0.16$ & $16.33 \pm 1.12$ \\
\hline
\end{tabular}

\subsection{FTIR Analysis}

Samples were also analyzed with a Fourier Transform Infra-Red (FTIR) spectrometer. The FTIR data is useful in quantifying the changes that take place within the solids during pyrolysis due to the fact that wave numbers can be associated with given sets of functional groups, thus allowing for an interpretation of the chemical changes that material goes through. In general, wave numbers between 400 and 1000 $\left(\mathrm{cm}^{-1}\right)$ correspond to $\mathrm{C}-\mathrm{H}$ bend bonds (aromatic and alkene groups that are not straight-chain molecules), 1000-1300 correspond to straight $\mathrm{C}-\mathrm{O}$ bonds (alcohols, ethers, esters, carboxylic acids), 1300-1470 correspond to $\mathrm{CH}_{2}$ and $\mathrm{CH}_{3}$ compounds, 1470-2000 correspond to straight $\mathrm{C}=\mathrm{C}$ and $\mathrm{C}=\mathrm{O}$ double bonds, 2100-2300 corresponds to straight Carbon-Carbon and Carbon-Nitrogen triple bonds and wave numbers greater than 2300 are usually associated with straight $\mathrm{C}-\mathrm{H}, \mathrm{N}-\mathrm{H}$ and $\mathrm{O}-\mathrm{H}$ bonds. [10-13] These wave number ranges are also provided in Table 5.

Table 5: Tabulated FT-IR spectra wave numbers, compiled from [10-13]

\begin{tabular}{lll}
\hline Wave Number Range & Bond Type & Examples \\
$400-1000$ & C-H (bend) & Aromatics and alkanes \\
$1000-1300$ & C-O (straight) & $\begin{array}{l}\text { Alcohols, ethers, esters, } \\
\text { carboxylic acids }\end{array}$
\end{tabular}




\begin{tabular}{lll}
\hline $1300-1470$ & $\mathrm{CH}_{2}$ and $\mathrm{CH}_{3}$ & Alkanes, alkenes \\
$1470-2000$ & $\begin{array}{l}\text { double bond carbon-carbon } \\
\text { and carbon-oxygen (straight) }\end{array}$ & $\begin{array}{l}\text { Amides, anhydrides, } \\
\text { esters, ketones }\end{array}$ \\
$2100-2300$ & $\begin{array}{l}\text { Triple bond carbon-carbon } \\
\text { and carbon-nitrogen } \\
\text { (straight) }\end{array}$ & Alkynes, nitrides \\
C-H, N-H, O-H (straight) & $\begin{array}{l}\text { Alcohols, phenols, } \\
\text { carboxylic acids }\end{array}$ \\
\hline
\end{tabular}

Figure 2 shows how the FTIR spectra for the coal vary between the initial feedstock and the resulting char for both the $850-1000$ and $300-500 \mu \mathrm{m}$ size ranges after heating to $500^{\circ} \mathrm{C}$. As can be seen, there is little change due to pyrolysis within the lower wave number band, corresponding to the aromatics, alkenes, ethers and esters groups. The spectra shows a significant reduction in the amount of $\mathrm{C}=\mathrm{C}$ and $\mathrm{C}=\mathrm{O}$ bonds following pyrolysis, and again with the higher wave numbers corresponding to the straight chain $\mathrm{O}-\mathrm{H}$ bonds (typically alcohols, phenols and carboxylic acids). This is in stark comparison with the spectra changes exhibited by the biomass material, as shown in Figure 3. In the case of the biomass, the more significant reductions occur within the lower wave number ranges corresponding to the aromatics, alkenes, ethers and ester groups, as well as the high wave number alcohols and phenol groups. In the cases involving coal, differences in particle size appear to have minimal impact on the FTIR spectra over the lower wave numbers. However, at higher wave numbers, the data suggests that smaller particle sizes leads to significant decreases in the transmittance. In comparison, the biomass spectra shows a much lesser dependence on particle size, with the primary differences being in the mid-range wave numbers corresponding to the $\mathrm{C}=\mathrm{C}$ and $\mathrm{C}=\mathrm{O}$ bonds.

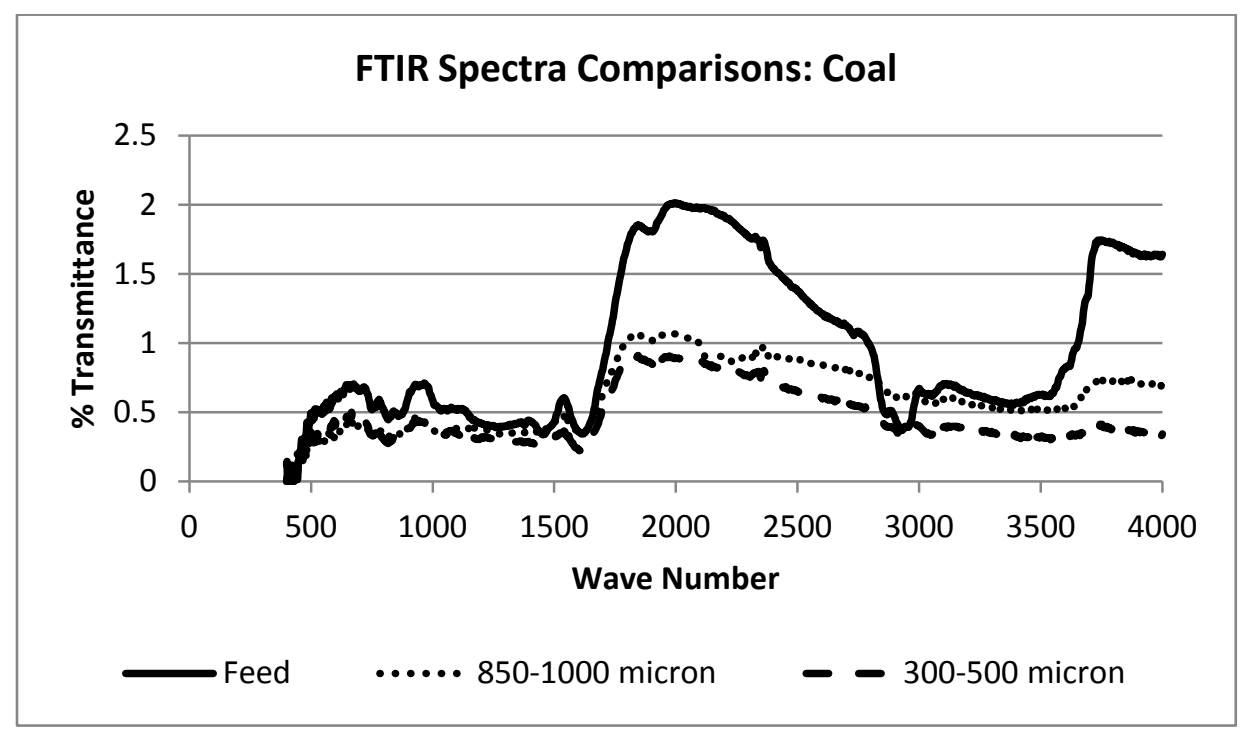

Figure 2.FTIR spectra for unheated feed coal, and coal chars after being heated to $500^{\circ} \mathrm{C}$. 


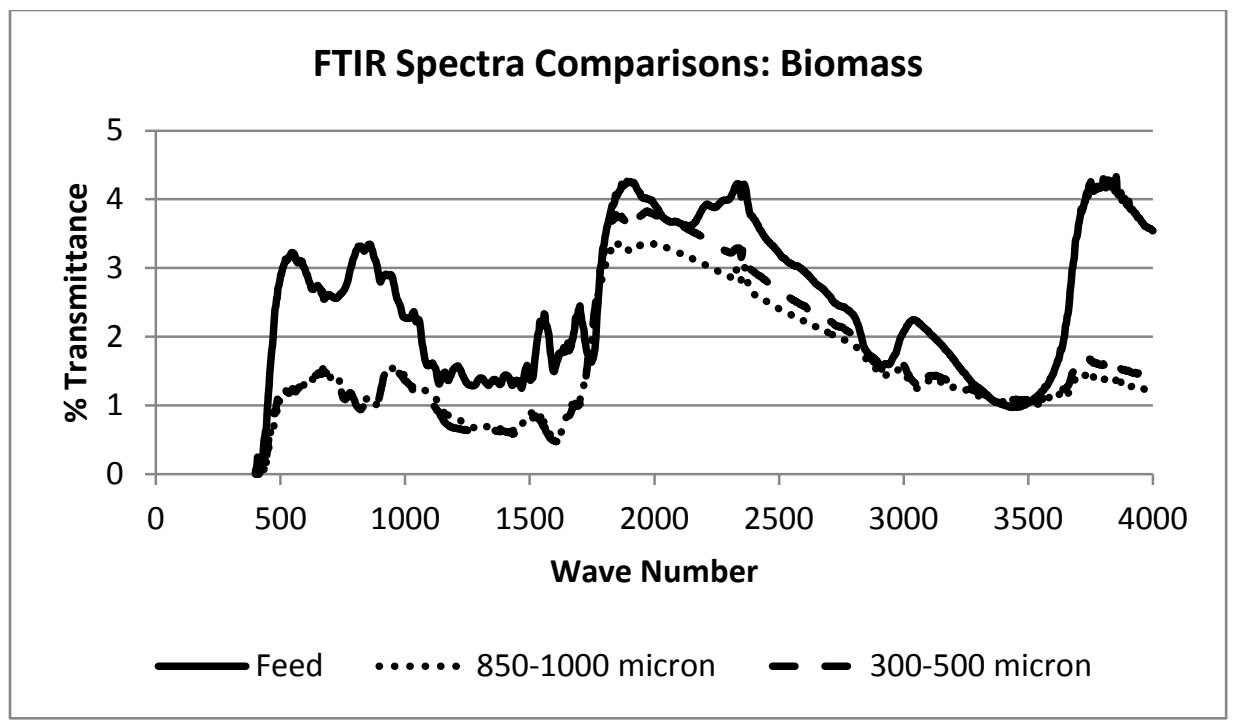

Figure 3.FTIR spectra for unheated feed biomass, and biomass chars after being heated to $500^{\circ} \mathrm{C}$.

Figures 4 and 5 shows the FTIR spectra for the experimental runs consisting of the pure coal, pure biomass and coal/biomass mixtures for the two particle size ranges, as well as a char mass weighted average of the pure coal- and pure biomass-derived char. The FTIR measurement typically yields a volumetric result, and while coal and biomass typically vary considerably in density, their chars are similar in density, thus a char-yield weighted average is an appropriate comparison basis for the 50/50 blend char spectra. It is apparent from examination of these figures that the FTIR spectra for the coal/biomass mixture agrees well with the weighted average plot for all but the lower wave number regions, suggesting a linear relationship within those higher wave number regions. However, the divergence between the coal/biomass mixture and the weighted average within the lower region corresponding to the aromatic and non-straight chain molecule $\mathrm{C}-\mathrm{H}$ alkene functional groups suggests a non-linear relationship between coal and biomass devolatilization within these types of chemical structures. It is possible the non-linearities observed by previous authors could be resulting from this particular phenomenon. 


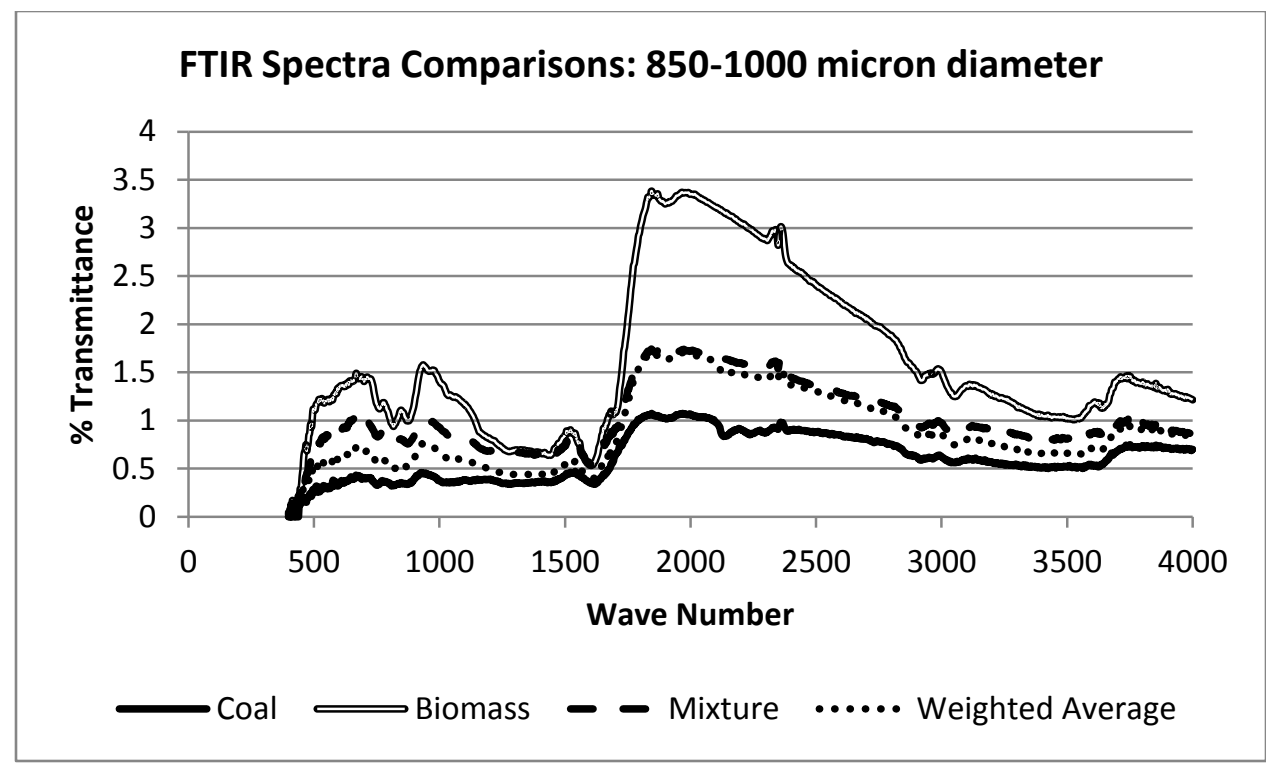

Figure 4.Comparison of spectra for different coal/biomass mixtures, 850-1000 micron particle size range after heating to $500^{\circ} \mathrm{C}$.

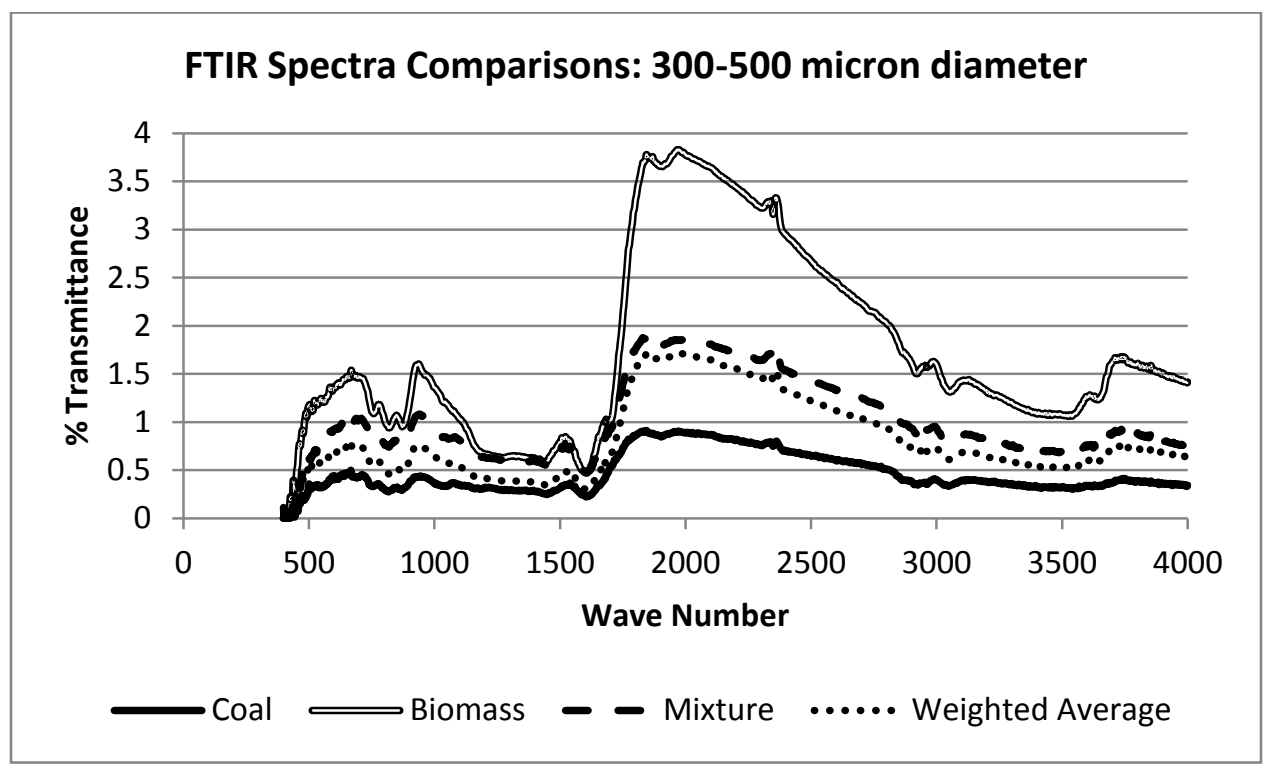

Figure 5.Comparison of spectra for different coal/biomass mixtures, 850-1000 micron particle size range after heating to $500^{\circ} \mathrm{C}$.

\section{Conclusions}

Several analytical techniques were used to characterize the effects of co-pyrolysis of coal and biomass on the chemical structure of the resulting char, as well as char and tar yields, and to determine whether or not a linear relationship existed between the coal and biomass when heated together. Experimental runs were conducted in which pure coal, pure biomass, and a 50/50 mixture of the two (by mass) were pyrolyzed. Evaluation of the char and tar mass yields a potentially nonlinear relationship with respect to tar yields; while proximate and ultimate analysis results provide evidence of a highly probable linear relationship between the coal and biomass, consistent with low heating rate co-pyrolysis of biomass with higher rank coal. Despite the fairly consistent evidence of a linear relationship between coal and biomass found in the 
ultimate analysis results, the result of the FTIR spectra analysis was less clear. These spectra showed evidence of non-linear effects of the coal and biomass mixture over the region corresponding to the aromatic and non-straight-chain alkene functional groups, while being linear with respect to other chemical structures. It is entirely possible that this finding could help explain why some of the previous authors who have studied the co-pyrolysis of coal and biomass have obtained results that suggest the existence of a non-linear relationship between the coal and the biomass at certain temperature ranges. These results support the earlier observations (Aboyade, et. al. [3]) of the potential presence of nonlinearities within the temperature range of $300-500^{\circ} \mathrm{C}$ during slow pyrolysis of coal and biomass mixtures. Additional exploration of chars produced at higher temperatures, as well as via flash pyrolysis, should be conducted, but was beyond the scope of the current study.

\section{Acknowledgements}

This technical effort was performed in support of the US-China Clean Energy Research Center Advanced Coal Technology Consortium's (CERC-ACTC) ongoing research in coal/biomass coconversion processes under the DOE contract DE-PI0000017. The authors would also like to thank the late Anthony "Femi" Olajide for all of the support and assistance he provided.

\section{References.}

[1] K.M. Lu, W.J. Lee, W.H. Chen, T.C. Lin, Thermogravimetric analysis and kinetics of co-pyrolysis of raw/torrefied wood and coal blends, Applied Energy 105 (2013) 57-65.

[2] M. Sami, K. Annamalai, M. Wooldridge, Co-firing of coal and biomass fuel blends, Prog energy Combust Sci. 27 (2001) 171-214.

[3] A. Aboyade, J. Görgens, M. Carrier, E. Meyer, J. Knoetze, Thermogravimetric study of the pyrolysis characteristics and kinetics of coal blends with corn and sugarcane residues, Fuel Processing Technology 106 (2013) 310-320.

[4] H. Haykiri-Acma, S. Yaman, Interaction between biomass and different rank coals during copyrolysis, Renewable Energy 35 (2010) 288-292.

[5] C. Ulloa, A. Gordon, X. Garcia, Thermogravimetric study of interactions in the pyrolysis of blends of coal with radiate pine sawdust, Fuel Processing Technology 90 (2009) 583-590.

[6] N. Weiland, N. Means, B. Morreale, Product distributions from isothermal co-pyrolysis of coal and biomass, Fuel 94 (2012) 563-570.

[7] J. Jones, M. Kubacki, K. Kubica, A. Ross, A. Williams, Devolatilisation characteristics of coal and biomass blends, J. Anal. Appl. Pyrolysis 74 (2005) 502-511.

[8] H. Vuthaluru, Thermal behavior of coal/biomass blends during co-pyrolysis, Fuel Processing

Technology 85 (2003) 141-155.

[9] R.M. Soncini, N.C. Means, N.T. Weiland, Co-pyrolysis of low rank coals and biomass: Product distributions, Fuel 112 (2013) 74-82.

[10] orgchem.colorado.edu/Spectroscopy/spectutor/irchart.pdf. Last viewed on 5/21/2014.

[11] www.chem.ucla.edu/ webspectra/irtable.html. Last viewed on 5/21/2014.

[12] wwwchem.csustan.edu/Tutorials/INFRARED.HTM. Last viewed on 5/21/2014.

[13] N. Colthup, Spectra-Structure Correlations in the Infra-Red Region, J. Opt. Soc. Am. 40 (1950) 397400. 